\title{
Maturity Models Architecture: A large systematic mapping
}

\author{
Erasmo L. Monteiro ${ }^{1}$, Rita S. Pitangueira Maciel ${ }^{1}$ \\ ${ }^{1}$ Computer Science Department - Federal University of Bahia (UFBA) \\ Ademar de Barros, s/n - Ondina - Salvador - Bahia, CEP 40.170-110 \\ erasmo.monteiro@dcc.ufba.br, rita.suzana@ufba.br
}

\begin{abstract}
Maturity models are widespread in research and in particular, IT practitioner communities. However, theoretically sound, methodologically rigorous and empirically validated maturity models are quite rare. This systematic mapping paper focuses on the challenges faced during the development of maturity models. More specifically, it explores the literature on maturity models and standard guidelines to develop maturity models, the challenges identified and solutions proposed. Our systematic mapping revealed over six hundred articles on maturity models. Extant literature reveals that researchers have primarily focused on developing new maturity models pertaining to domain-specific problems and/or new enterprise technologies. We find rampant re-use of the design structure of widely adopted models such as Nolan's Stage of Growth Model, Crosby's Grid, and Capability Maturity Model (CMM). We also identify three dominant views of maturity models and provide guidelines for various approaches to constructing maturity models with a standard vocabulary. We finally propose using process theories and configurational approaches to address the main theoretical criticisms with regard to maturity models and conclude with some recommendations for maturity model developers.
\end{abstract}

Keywords. Maturity Model. Capability maturity model. Stage of growth. Maturity grid. Systematic mapping.

\section{Introduction}

Maturity can be understood as a state or condition that is explicitly defined, managed, measured, and controlled ([CMMI 2010], [Mettler, Rohner and Winter 2010]). Maturity models are used to facilitate benchmarking of internal and/or external organizational processes, providing guidelines for corporate growth and often present levels or stages for future improvements. Maturity models usually follow a stage growth approach, presenting maturity levels in a linear and unidirectional path, from the lowest to the highest [Duane and OReilly 2012]. They can be used in different domains, generally used for the systems evolution understanding and processes.

In recent years there has been a dramatic growth in interest in maturity models for different domains, such as web and social media ([Duane and OReilly 2012], [Lehmkuhl, Baumol and Jung 2013]), analysis ([Davenport et al. 2007], [Cosic et al. 2012]), the consulting area ([Delloitte 2012], [Accenture 2013]). There have also been

Cite as: Monteiro, E.L. \& Maciel, R. S.P.(2020). Maturity Models Architecture: A large systematic mapping. iSys: Revista Brasileira de Sistemas de Informação (Brazilian Journal of Information Systems), 13(2), 110140. 
several investigations into the development of maturity models, such as in design science and procedure models to aid in the development of these models ([Becker, Knackstedt and Pöppelbuß 2009], [De Bruin et al., 2005], [Solli- Sæther and Gottschalk 2010]). Certifications, which began with the advent of the Capability Maturity Model ([Paulk et al., 2006], [CMMI 2010]), have motivated consultants to develop some models for several purposes. Despite their popularity, maturity models have been criticized for lack of empirical validation, misguided structural assumptions and for being too simplistic to be useful [Plattfaut et al. 2011]. Difficulties arise when comparing models for the same domain, due to the lack of a standard vocabulary, which hampers their adoption.

This paper presents a systematic mapping that aims to identify the standard vocabulary, as well as to indicate which strategies of specification and evaluation are used. Sharing the knowledge about these models specification may assist in specifying others as well as increasing confidence. Additionally, pre-use assessment can increase reliance as it shows that errors have already been corrected and the model is an improved version of previous ones.

This review follows the guidelines proposed by Kitchenham et al. (2007) and (Kitchenham, 2004). The remainder of this paper is organized as follows: Section 2 presents the theoretical justification (background); Section 3 shows related work; Section 4 shows the research method used to guide this systematic mapping; Section 5 shows the planning of the mapping; Section 6 introduces the execution of the mapping, which is summarized in section 7; In Section 8 we detail some threats to our mapping and how they can be minimized; Finally, in Section 9, the conclusions and future works are presented.

\section{Background}

This section presents basic and related concepts and classifications of maturity models.

Maturity models are used to facilitate the benchmarking of internal and/or external organizational processes and can provide guidelines for corporate growth. A maturity model can broadly be used as a way to assess how skilled an organization is in managing its projects and its current maturity for example. Helping to identify what level of maturity an organization is at, helps to define the best path for the next steps to be achieved. Generally, maturity models are composed of: (i) maturity levels; (ii) a summary of the characteristics and an indication of what the organization should focus on at each level; and (iii) a method to determine the organization position within the model. The models usually range from 3 to 6 levels and can be differentiated by the paradigm/approach used as a base, as well as the dimensions and levels of content. Some examples can be placed in this category: (a) CMM-Capability Maturity Model and CMM-based, such as MPS.BR; (b) SCPM3 (Supply Chain Process Management Maturity Model); (c) OPM3 (Organizational Project Management Maturity Model); (d) PMMM (Project Management Maturity Model) ([Crosby 1980] [Bessant, Caffyn and Gallagher 2001] [Garrett and Rendon 2005] [Lockamy and McCormack 2004] [McCormack et al. 2009]).

Maturity levels, which are also called stages, are used to describe the maturity of the target analyzed entity. The dimensions are critical factors for success, and may also contain subcategories. Finally, the maturity path usually follows linearly, from the 
lowest to the highest maturity level, and growth is evolutionary [Carvalho, J. V. et al, 2017]. Maturity models can be composed of two parts: the first one, comprising the stages, dimensions, and subcategories, and the second one, describing the hierarchical relationships between the typical components of the maturity model [De Bruin et al. (2005)]. Although maturity levels suggest improvement in processes, as described in maturity models, there is a little evidence that incremental levels provide improvements in process maturation [Mullaly 2014]. According to [Andersen and Henriksen 2006], the scores, stages or levels, are speculative measures that should be used for comparative process evaluation in a company, but that commonly do not exert this function.

To assist the specification of a maturity model, two approaches are used: (i) topdown, defining stages, creating dimensions, adjusting measures and definitions; (ii) bottom-up, the requirements and measures are initially determined and then stages are defined, However, there is no consensus among maturity model developers as to what and when an approach should be applied [Anza, F. A, et al, 2017]. De Bruin et al. (2005) claim that the top-down approach works for a relatively new domain as there is little evidence of what is maturity among the community. On the other hand, in a wellestablished domain, the focus is on how maturity is measured rather than what maturity represents, thus requiring the bottom-up approach. That said, Solli-Sæther et al. (2010) propose following a step-by-step recipe irrespective of the newness of the domain. Therefore, it can be concluded that there are no hard and fast rules to decide on the approach, but it is important to use existing literature and validate the dimensions and constructs of maturity models empirically.

According to Royce (2002), the Capability Maturity Model (CMM) was developed by the Software Engineering Institute (SEI) and was designed explicitly for maturing software process. However, with its successful adoption, CMM models have been used in different domains, adapted and developed for disciplines and more specific functions such as systems engineering, people, integrated product development, software acquisition, among others [Royce 2002]. Some cases associated with CMM practice show symptoms of the traditional cascading model, with excessively management-based processes. This resulted in linking CMM-based organizations to the principles of cascading mindset, giving them a negative connotation.

National Quality Awards and Standards are often used as a Maturity Model synonym in the literature. Although they have some similarity, there are many essential differences between them [Singh and Smith 2006]. National Quality Awards are often based on criteria to evaluate a particular company and refer to its excellence in management aspects. They are designed to present management practices, and they are used to stimulate the development of the corporate culture, granting public recognition to the companies with satisfactory results. Some examples include: (i) Malcolm Baldrige National Quality Award (United States); (ii) European Foundation Quality Management (EFQ) [EFQM 2011] [Bemowski 1996].

Standards guide organizations to achieve success by relying on a quality management approach (generally an evolution of the model prescribed by ISO 9001) and they apply to any organization, regardless of size, type, and activity. Some approaches are in this category: (i) ISO 9004; (ii) JIS Q 9005 [ABNT 2010] [JIS 2005]. 
Standards determine the requirements based on the continuous improvement cycle, known as PDCA (Plan, Do, Check, Act or Adjust).

Maturity models are different from National Quality Awards and Standards in a number of respects. The standards provide guidance to organizations for the achievement of sustained success by using a quality management approach while National Quality Awards are based on criteria and evidence used to assess an organization and refer to management excellence. They set parameters, which reflect excellence, such as Leadership, people, policy and strategy.

\section{Related work}

Maturity models have been attracting academic attention recently. During the development of this mapping, we identified some similar works.

In 2010, Becker published a paper suggesting that theoretical assumptions were needed to determine maturity and create models. He also verified which topics of interest were being studied and concluded that research on maturity models is still relevant and has potential.

In 2011, Pöppelbuß et al. analyzed 76 papers about maturity models published in conference and Information Systems journals in the last 15 years, from three perspectives: (i) academic, helping other researchers in the design and adoption of maturity models, indicating which models are most popular; (ii) publication, indicating the interests of authors and reviewers and determining which types of events were most used for publications, and; (iii) industrial, helping potential users, summarizing practical implications, and discussing conceptual and structural issues that are supportive of consultants. They found that CMM is the most dominant foundation of research in maturity models. On the other hand, theories on designing and adopting maturity models are undoubtedly rare. The publications exhibit empirical, quantitative and qualitative research, but, with a few being purely conceptual research.

Finally, in [Wendler 2012], a literature review was motivated by the increase in the number of publications on this topic and by the lack of papers that summarize results. The main goals were the identification of state of the art and the research gaps in papers found in journals and conferences. As a result, the mapping of 237 papers showed that current research in the maturity model applies to more than 20 domains, heavily dominated by software development and software engineering. The study revealed that most publications deal with the development of maturity models and empirical studies. The relationship between conceptual development and designoriented development was analyzed, indicating that there is still a gap in the evaluation and validation of the models developed.

Although these works dealt with maturity models, this paper differs from them regarding scope and objectives, as we are interested in how maturity models have been specified and how maturity models have been evaluated. This knowledge could help towards systematization for the development of new maturity models.

\section{Research Method}

The systematic mapping was conducted by two researchers from the area and follows the guidelines presented in [Kitchenham 2004], which are composed of three phases: 
planning, execution and abstract (summarization). Figure 1 provides an overview of the adopted search method.

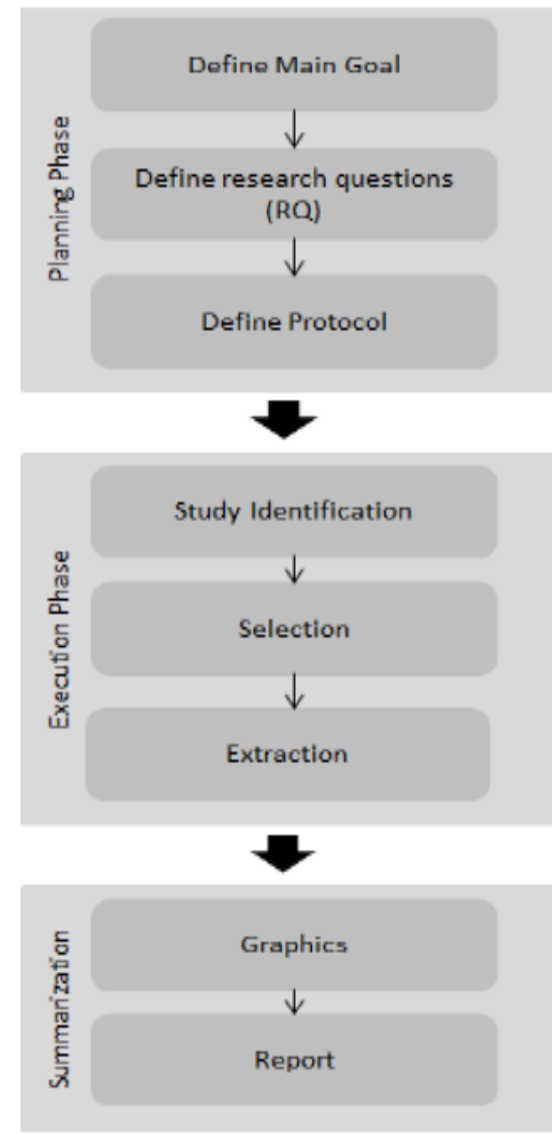

Figure 1. Overview of the research method (Kitchenham, 2004)

During the planning phase, we defined the primary goal of systematic mapping. Then five research questions (two main and three secondary) were specified, expressing aspects to be observed in the literature to answer the main objective, followed by the search string, search bases, and inclusion/exclusion criteria specifications. To analyze the selected papers, we used a checklist adapted from [Kitchenham, Mendes and Tarek 2007], Section "Study Quality Assessment Checklists."

In the second phase, the execution phase, a systematic mapping was executed according to the protocol. In the first step, second phase, study identification, the search string was used to check the papers in each search base automatically and 638 papers were found. Then, the title, author, keyword, abstract and year were extracted to proceed with the selection. In the selection phase, the inclusion and exclusion criteria were applied to identify the relevant studies. This process involved analysis of the title, abstract and introduction. Initially, we analyzed the title to verify the relevance of our research. Then we proceeded with the reading of the abstract. For those papers where we were unable to guarantee relevance through title and abstract analysis, the introduction was read. For the 66 papers selected we looked at the author's list of publications to ensure that we were using their most recent publications. Finally, in the 
third phase, extraction, we analyzed the full text of the selected papers, a total of 38 . The third phase, summarization, reported the results of the study.

\section{Planning}

In this paper, we shall address these objectives: (a) review the state of the art, (b) identify how maturity models were evaluated, (c) identify the types of models, based on the creation/derivation of the dimensions and their levels, (d) identify a generic structural representation of a maturity model, (e) identify which theoretical foundations were used to develop the models.

The following are the mapping primary research questions:

(a) RQ 01: What are the approaches and design structures for specifying a maturity model?

(b) RQ 02: What are the evaluation and validation methods applied in maturity models?

The questions below present secondary research questions to support the understanding of the research questions.

(i) SRQ: What are the types and generic methods for developing maturity model?

(ii) SRQ: What are the characteristics and definitions to use while developing maturity models?

(iii) SRQ: What are the theoretical considerations that help while developing maturity models?

The goal of these research questions is to obtain results about design (strategies, vocabulary, and methodologies used in the maturity models specification processes), and methods for their validation and evaluation.

\subsection{Search bases and Search String.}

In order to retrieve the papers, a search string was applied the digital databases including ACM, IEEE Explore, Springer, and basket of eight journals. As there are some syntax differences among these search engines of these databases, a search string between the bases was defined to guarantee the consistency of the search, observing the possibility of combinations and insertion of selection criteria such as title, abstract and keywords. The generic sequence of searches with the combination of keywords aims to find studies that help to answer the questions proposed. For more accuracy in the ACM Digital Library we created a specialized search string.

○ Generic Search string: ("maturity model" OR "stage of growth" OR "capability maturity" OR "maturity grid" OR "standard" OR "framework") AND ("design" "construction" "development" "architecture") AND ("evaluation OR assessment")

○ ACM Digital Library: TITLE-ABSTR-KEY(+("maturity model" "stage of growth" "capability maturity" "maturity grid" standard framework) $+($ design construction development architecture) +(evaluation assessment)

In this study there was no criterion of selection of papers regarding year, we considered all the papers published and which had the topic covered in the 
abstract/title/introduction. The year of publication was considered to identify the evolution of investigations related to maturity models.

\subsection{Scope and Extraction Criteria}

In this section the selection criteria are shown (about paper content). The papers had to fulfill one of the criteria in order to be selected:

○ Detailed documentation of the development process; e.g., the papers must build a new maturity model.

- Use of empirical methods in the construction or implementation of maturity models.

Discussion of the process of creating the models, informing the principles and guidelines.

Table 1. Quality criteria

\begin{tabular}{|c|c|}
\hline Question & Score \\
\hline 1. Are the research aims clearly specified? & $\begin{array}{l}\text { Y/ N/ } \\
\text { Partial }\end{array}$ \\
\hline 2. Was the study designed to achieve these aims? & $\begin{array}{l}\text { Y/ N/ } \\
\text { Partial }\end{array}$ \\
\hline $\begin{array}{l}\text { 3. Are the used techniques clearly described and their selection } \\
\text { justified? }\end{array}$ & $\begin{array}{l}\mathrm{Y} / \mathrm{N} / \\
\text { Partial }\end{array}$ \\
\hline 4. Are the variables considered by the study suitably measured? & $\begin{array}{l}\text { Y/ N/ } \\
\text { Partial }\end{array}$ \\
\hline 5. Are the data collection methods adequately described? & $\begin{array}{l}\mathrm{Y} / \mathrm{N} / \\
\text { Partial }\end{array}$ \\
\hline 6. Is the data collected adequately described? & $\begin{array}{l}\text { Y/ N/ } \\
\text { Partial }\end{array}$ \\
\hline 7. Is the purpose of the data analysis clear? & $\begin{array}{l}\mathrm{Y} / \mathrm{N} / \\
\text { Partial }\end{array}$ \\
\hline $\begin{array}{l}\text { 8. Are statistical techniques used to analyze data adequately } \\
\text { described and their use justified? }\end{array}$ & $\begin{array}{l}\mathrm{Y} / \mathrm{N} / \\
\text { Partial }\end{array}$ \\
\hline 9. Are negative results (if any) presented? & $\begin{array}{l}\mathrm{Y} / \mathrm{N} / \\
\text { Partial }\end{array}$ \\
\hline $\begin{array}{l}\text { 10. Do the researchers discuss any problems with the } \\
\text { validity/reliability of their results? }\end{array}$ & $\begin{array}{l}\mathrm{Y} / \mathrm{N} / \\
\text { Partial }\end{array}$ \\
\hline 11. Are all research questions answered adequately? & $\begin{array}{l}\text { Y/ N/ } \\
\text { Partial }\end{array}$ \\
\hline $\begin{array}{l}\text { 12. How clear are the links between data, interpretation, and } \\
\text { conclusions? }\end{array}$ & $\begin{array}{l}\mathrm{Y} / \mathrm{N} / \\
\text { Partial }\end{array}$ \\
\hline 13. Are the findings based on multiple projects? & $\mathrm{Y} / \mathrm{N} /$ \\
\hline
\end{tabular}


The search found more than 600 academic papers, indicating the popularity of maturity models. A considerable amount of literature has been published over the past two decades, probably due to technological developments. The filters recommended by [Webster and Watson 2002] were applied due to the vast number of publications.

Some filters were used in order to guarantee the quality of the selected papers: (i) filter 1: removal of duplicate papers; (ii) in filter 2, the titles and abstracts were read in order to verify if the purpose of the paper was in agreement with our research questions; (iii) in filter 3: Introduction, background, and conclusion were read, and the quality was evaluated through a checklist, seen in Table 1 below, adapted from [Kitchenham, Mendes and Tarek 2007]. One of the researchers applied Filter 1 and 2, removing the duplicates, reading title, abstract and selecting candidate papers, while the other researcher used filter 3. At times, there were disagreements and they were resolved through a face-to-face meeting in which the whole paper was read.

Table 1 presents the questions, and each of the 13 search questions has 1.0 point, if the answer is "yes," 0.5 points if the answer is "partial" and 0 points if the answer is "no." As a result, each paper could obtain between 0 and 13 points.

The first quartile of questions $(13 / 4=3.25)$ was used as a cutting point for the inclusion of the papers. A paper with a final score below 3.25 was excluded from the final list to avoid low-quality papers. Exclusion criteria were used to ensure that the selected papers obtained a minimum score in the methodology used (rigor).

\section{Execution}

Table 2 summarizes that the statistical data of our extraction procedure in each search base.

Table 2. Summary of the papers found

\begin{tabular}{|l|l|l|l|l|}
\hline \multicolumn{1}{|c|}{ Search Bases } & \multicolumn{1}{|c|}{$\begin{array}{c}\text { No } \\
\text { filter }\end{array}$} & $\begin{array}{c}\text { With filter } \\
\mathbf{1}\end{array}$ & $\begin{array}{c}\text { With filter } \\
\mathbf{2}\end{array}$ & $\begin{array}{c}\text { Relevant works (with } \\
\text { filter 3) }\end{array}$ \\
\hline ACM & 211 & 139 & 28 & 15 \\
\hline IEEE eXplore & 107 & 71 & 16 & 11 \\
\hline Springer & 298 & 197 & 39 & 5 \\
\hline $\begin{array}{l}\text { Basket of eight } \\
\text { journal }\end{array}$ & 7 & 5 & 1 & 1 \\
\hline Others & 15 & 11 & 10 & 6 \\
\hline Total & 638 & 423 & 94 & 38 \\
\hline
\end{tabular}

We checked the "Basket of Eight" which resulted in 7 papers, however, only one of them was selected, [Damsgaard and Scheepers 1999]. The search was then expanded to other journals in the AIS electronic library, resulting in 11 more papers, of which four were selected, such as [Van Steenbergen et al. 2013], [Becker, Knackstedt and Pöppelbuß 2009], [Pöppelbuß et al. 2011] and [Wendler 2012]. We also expanded the 
research to the other databases, such as Google Scholar, Web of Science and Scopus, resulting in 138 papers that were read and analyzed in detail, of which 7 were selected. Furthermore, important papers, such as [Nolan and Gibson 1974], [Crosby 1980], [King and Kræmer 1984], [Paulk et al. 2006], were also added. These 15 papers are represented in "others" in the table below. Finally, we used 38 papers to make final recommendations.

Figure 2 shows the step sequence performed in the study selection process and the resulting quantity of papers for each step respectively.

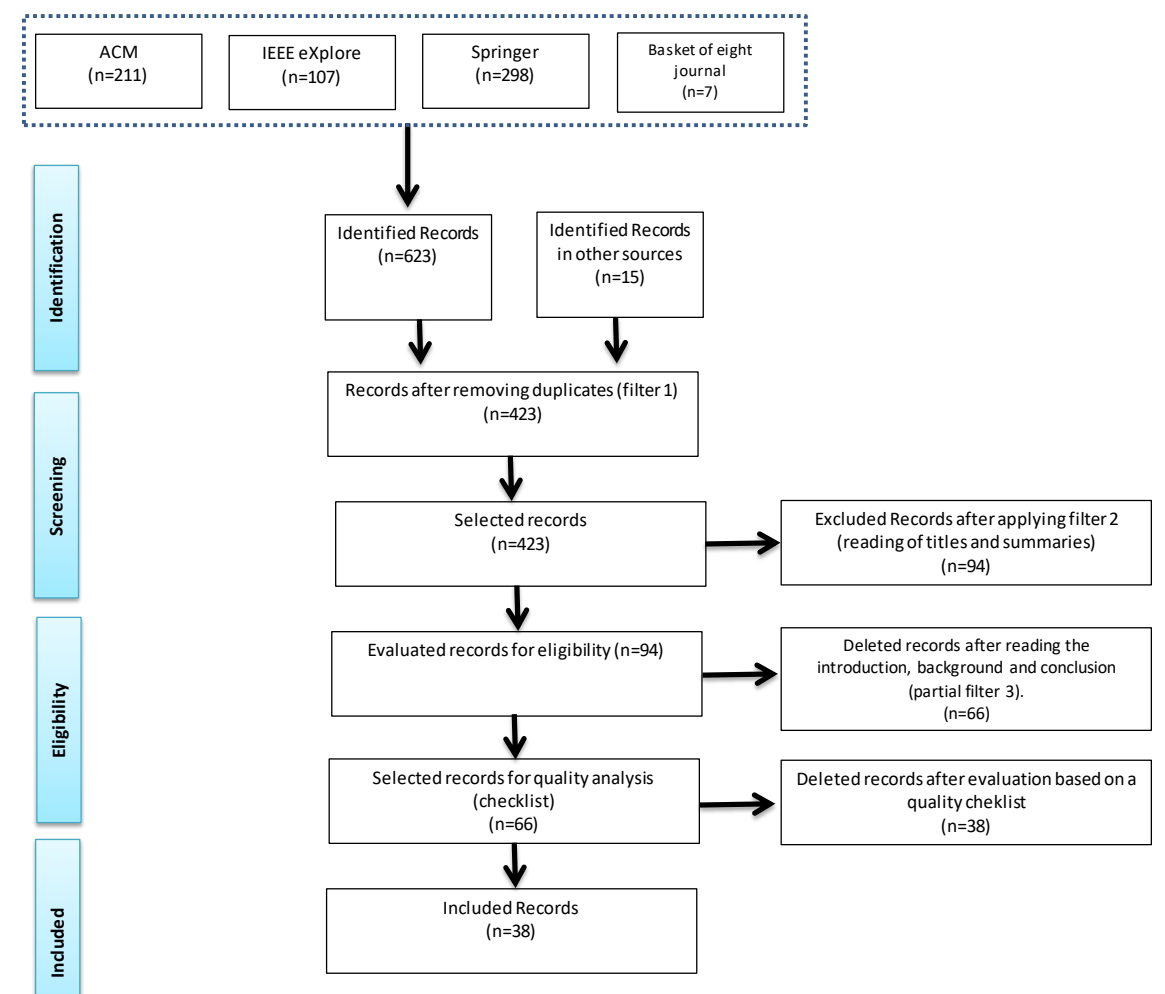

Figure 2. Stages of the study selection process

\section{Summarization}

The following is a summary of results that were found in systematic mapping. Figure 3 shows a distribution of primary studies by publication year. 


\section{Publications per year}

- Quantity of papers

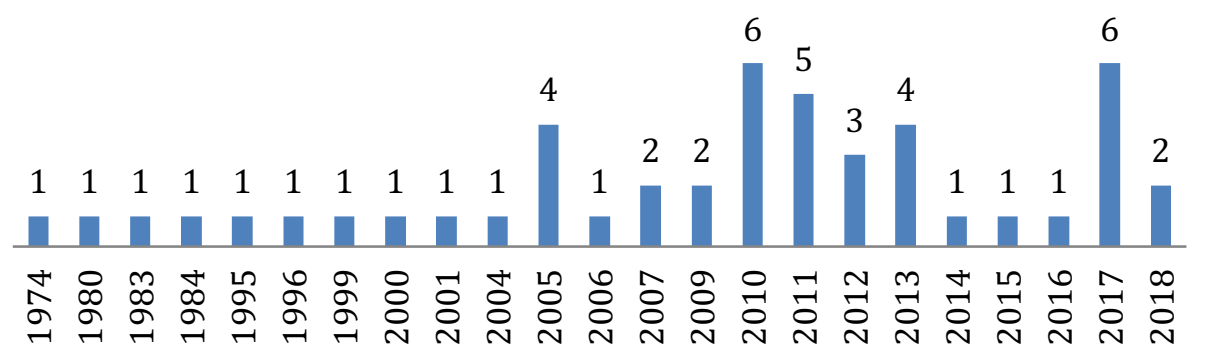

Figure 3. Distribution of primary studies by publication year. 


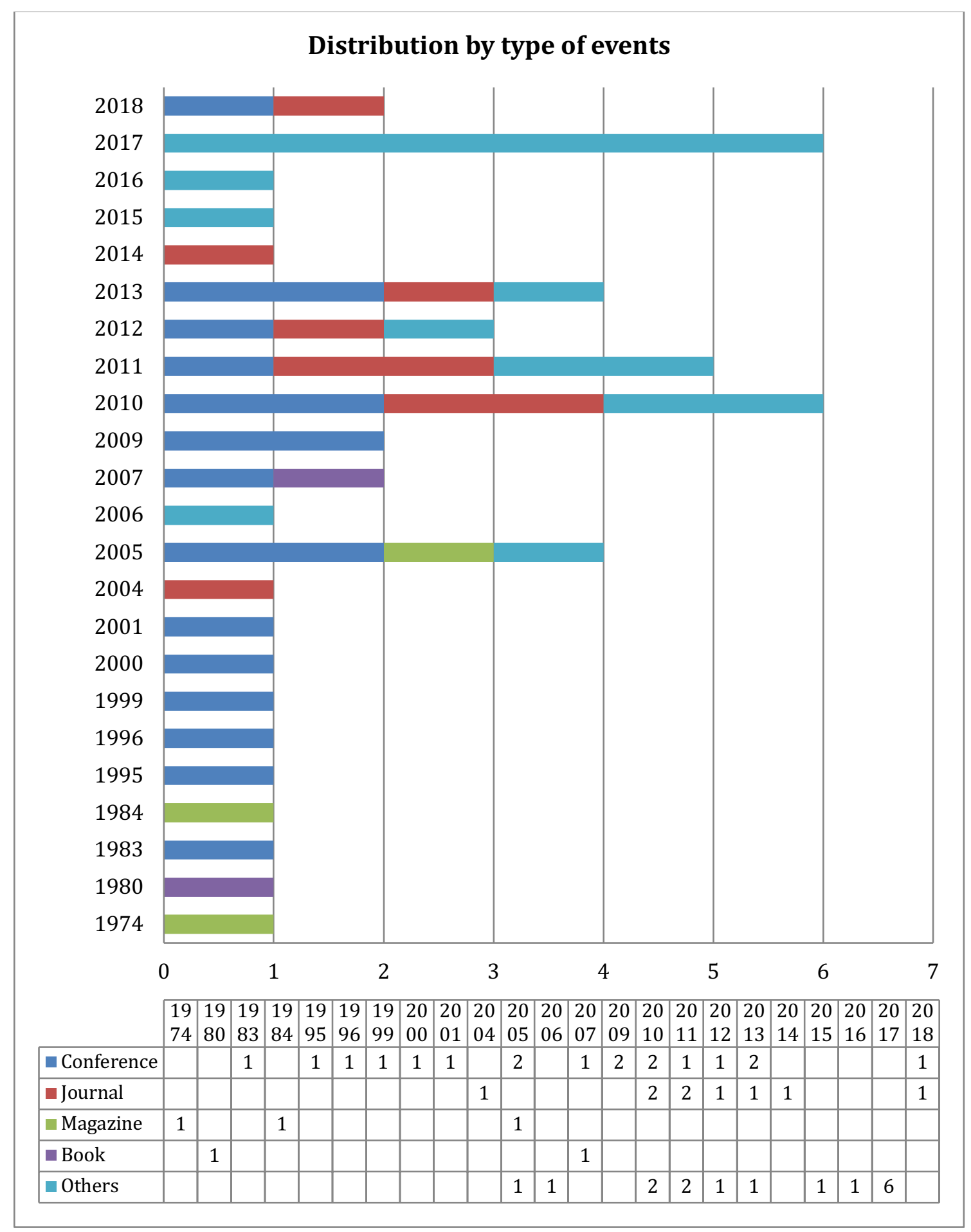

Figure 4. Distribution by type of events.

Figure 3 presents the distribution of 48 papers, however, a total of 38 constituted the literature corpus to make the final recommendations and background. The years 2010, 2011 and 2017 had the most publications. What stands out is the variability of interest in maturity models which could be motivated by the emergence and disappearance of new technologies and the application domain variation. In recent years some papers have been found, such as in 2015 (Frezattiet et al), 2016 (Petter O'donovan et al) , 2017 [(Hackos, J.T) (Anza, F. A) (Carvalho, J. V. et al) (Rodríguez, 
N. H. and Carreira, M. R.) (Correia, E. et al) (Henriques, Vaughan, and Tanner, M)] and some papers in 2018, like (Carvalho, Pereira and Rocha, 2018) and (Carvalho et al. 2018), were used to compose the background.

The results obtained from the analysis of distribution by type of events are presented in Figure 4. Figure 4 presents a summary, highlighting the temporal distribution of our selected papers, grouped according to publication and showing the number of publications by year and type of event. From Figure 4, it can be seen that by far most publications are at a conference, probably because it requires less academic rigor. Table 3, Table 4 and Table 5 present the selected papers in this systematic mapping.

Table 3. Related papers via mapping (In the 1970 s and 1980s)

\begin{tabular}{|c|c|}
\hline Decade & Title \\
\hline 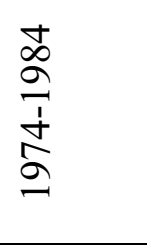 & $\begin{array}{l}\text { [S1] [Nolan and Gibson 1974] Managing the Four Stages of EDP Growth; } \\
\text { [S2] [Crosby] Quality Is Free: The Art of Making Quality Certain; [S3] } \\
\text { [Drury] An Empirical Assessment of the Stages of DP Growth; [S4] [King } \\
\text { and Kraemer] Evolution and organizational information systems: an } \\
\text { assessment of Nolan's stage model }\end{array}$ \\
\hline
\end{tabular}

This table is quite revealing for several reasons. First, the papers showed the need to manage organizational growth through stages. Second, it is demonstrated that process control is critical and essential to the overall quality of the organization. Third, the model proposed by Nolan was investigated, and as a result, problems in the formulation were found, which could explain the lack of validation of the model.

In S1, the authors showed the need to manage the growth of departments, in hardware, software and people requirements in stages. A 4-stage maturity model is presented and indicated which requirements are required to reach the higher stages.

In $\mathrm{S} 2$, it is demonstrated that process control is critical to the overall quality of the organization and achieving success.

In $\mathrm{S} 3$, this paper tried to validate the hypotheses prescribed by Nolan (S1), through the analysis of data obtained in the benchmarks.

In S4 the model proposed by Nolan (S1) was investigated through an empirical analysis. Problems in the formulation were found, which could explain the lack of validation of the model.

Closer inspection of the table (above) shows that four theories (life cycle, teleology, dialectics, and evolution) were presented. Second, new metrics were presented to measure the growth in performance of a company. Third, some proposals for the development of a maturity model were presented, as well as a reference model, indicating a growing interest in development methodologies.

In S5, four theories were presented: life cycle, teleology, dialectics, and evolution. In the paper, an application of each theory is demonstrated, and the author proposes an interaction between them to collaborate towards organizational development. 
In S6, new metrics were presented to measure the growth performance of a company, reducing redundancy, increasing usability and defining more general criteria.

In S7, a four-stage growth model for intranet implementation and management is proposed to ensure the planning, organization, and control of activities associated with the management of the computational resource.

Table 4. Related papers via mapping (from 1995 to 2005)

\begin{tabular}{|c|c|}
\hline Decade & Title \\
\hline $\begin{array}{l}\mathscr{8} \\
8 \\
\text { ஸे } \\
\stackrel{2}{2} \\
2\end{array}$ & $\begin{array}{l}\text { [S5] [Van De and Poole] Explaining Development and Change in } \\
\text { Organizations; [S6] [Bemowski] Baldrige award celebrates its 10th birthday } \\
\text { with a new look; } \\
\text { [S7] [Damsgaard and Scheepers] Managing the crises in intranet } \\
\text { implementation: a stage model; } \\
\text { [S8] [Luftman] Assessing Business-IT Alignment Maturity; [S9] [Bessant, } \\
\text { Caffyn and Gallagher] An evolutionary model of continuous improvement } \\
\text { behavior; } \\
\text { [S10] [Renken] Developing an IS/ICT management capability maturity } \\
\text { framework; [S11] [Lockamy and McCormack] The development of a supply } \\
\text { chain management process maturity model using the concepts of business } \\
\text { process orientation; [S12] [De Bruin et al.] Understanding the Main Phases of } \\
\text { Developing a Maturity Assessment Model; [S13] [Garrett and Rendon] } \\
\text { Managing contracts in turbulent times: the contract management maturity } \\
\text { model; [S14] [JIS] Quality Management System: guidelines for sustainable } \\
\text { growth; [S15] [De Bruin et al.] Towards a Business Process Management } \\
\text { Maturity Model }\end{array}$ \\
\hline
\end{tabular}

S8 presented an approach that evaluates maturity between business and information technology to identify opportunities for improvement.

S9, this paper presented a case study that demonstrated the relationship between continuous improvement and capacity evolution. Then, a reference model is proposed to evaluate this progress.

In $\mathrm{S} 10$, a framework is proposed and seven indicators, which compose the framework, are combined. Then an evaluation of the maturity level is performed using the seven indicators to obtain an organizational profile. The author states that the framework is an essential tool to evaluate the capacity of a company and can be used to compare or obtain a maturity profile for a given domain.

$\mathrm{S} 11$, this paper examined the relationship between maturity and the supply chain, focusing on its performance in the management process. A maturity model is proposed to guarantee a better performance in the processes of the supply chain.

In S12, the authors indicated that the development phases of a model are not generalized for any domain and then proposed a methodology, describing the main phases for the development of a generic model 
In S13, a stage-based maturity model was proposed to manage contracts to improve the competitive advantage of the company.

In $\mathrm{S} 15$, a maturity model was proposed for the organization's business processes.

Table 5. Related papers via mapping (from 2005 to 2016)

\begin{tabular}{|l|l|}
\hline Decade & \multicolumn{1}{|c|}{ Title } \\
\hline $2006-$ & [S16 ] [Paulk et al.] Capability maturity model, version 1.2; [S17] \\
[Davenport and Harris] Competing on Analytics: The New Science of \\
Winning; [S18] [Kitchenham, Mendes and Travassos] A Systematic \\
Review of Cross- vs. Within-Company Cost Estimation Studies; [S19] \\
[McCormack et al.] A global investigation of key turning points in business \\
process maturity; [S20] [Becker, Knackstedt and Pöppelbuß] Developing \\
Maturity Models for IT Management; [S21] [CMMI] CMMI for \\
Development, Version 1.3 (CMU/SEI-2010-TR-033); [S22] [ABNT] NBR \\
ISO 9004; [S23] [Solli-Sæther and Gottschalk] The modeling process for \\
stage models; [S24] [Mettler, Rohner and Winter] Towards a Classification \\
of Maturity Models in Information Systems; [S25] [El Sawy et al.] \\
Research Commentary Seeking the Configurations of Digital Ecodynamics: \\
It Takes Three to Tango; [S26] [Becker et al.] Maturity Models in IS \\
Research; [S27] [Pöppelbuß et al.] Maturity Models in Information Systems \\
Research: Literature Search and Analysis; [S28] [Fiss] Building better \\
causal theories: A fuzzy set approach to typologies in organization research; \\
[S29] [EFQM] EFQM; [S30] [Back and Haager] Assessing Degrees of \\
Web-2.0-ness for Websites: Model and Results for Product Websites in the \\
Pharmaceutical Industry; [S31] [Plattfaut et al.] Development of BPM \\
capabilities - Is maturity the right path?; [S32] [Wendler] The maturity of \\
maturity model research: A systematic mapping study; [S33] [Duane and \\
OReilly] A Conceptual Stages of Growth Model for Managing an \\
Organization's Social Media Business Profile (SMBP); [S34] [Delloitte] \\
European eCommerce Assessment 2012 Benchmarking the top 200 in \\
online retail; [S35] [van Steenbergen] Improving IS Functions Step by Step: \\
the Use of Focus Area Maturity Models; [S36] [Raber, Wortmann and \\
Winter] Situational Business Intelligence Maturity Models: An Exploratory \\
Analysis; [S37] [Lehmkuhl, Baumol and Jung] Towards a Maturity Model \\
for the Adoption of Social Media as a Means of Organizational Innovation; \\
[S38] [Delta] The Accenture Netherlands Analytics DELTA Survey 2013; \\
[S39] [Cleven et al.] Process management in hospitals: an empirically \\
grounded maturity model.
\end{tabular}

What is interesting about the data in the table above is the increase in the number of proposals using a systemic and holistic perspective for the construction and testing of maturity models. Some authors presented a critical view of maturity models and conducted a case study for validation.

$\mathrm{S} 17$, this paper presented the statistical characteristics and practices and described some changes in the processes that companies must adhere to in order to obtain competitive advantages in a quantitative territory. 
S18, the objective of this paper was to present the circumstances in which organizations can believe and trust in the results after applying some maturity model.

S19 presented the necessary characteristics to implement BPM as support for the maturity process.

S20, this paper presented a proposal for a model that supports the development of maturity models to improve the process.

S23 presented and tested a method to develop models because of the importance of having something theoretically and validly empirical.

S24 presented an approach for the classification of maturity models to facilitate their search and selection.

S24 presented an approach for the classification of maturity models to facilitate their search and selection.

S25, the authors proposed a systemic and holistic perspective for the construction and testing of maturity models, based on strategic management.

S26 presented the implications when applying maturity models.

S27, this paper collected and analyzed seventy-six articles on maturity models published in Information Systems journals and conferences over the past fifteen years. The authors analyzed the papers from three perspectives: research, publication and professional.

S28, typologies are an important way of organizing the complex cause-effect relationships that are key building blocks of the strategy and organization literature. The author develops a novel theoretical perspective on causal core and periphery, which is based on how elements of a configuration are connected to outcomes.

S30, this paper described the development of a maturity model to evaluate Web2.0. The model was based on O'Reilly's Web 2.0 principles and standards.

In 31, the authors presented a critical perspective of BPM-based maturity models and conducted a case study. They found that orientation based on maturity models may become inadequate if the organization's environment is not considered.

In S32, state of the art on maturity models and research gaps are analyzed.

S33, in this paper, the authors proposed a conceptual model of Growth Stages to manage a company's Social Media Business Profile. model."

$\mathrm{S} 35$, in this paper, the authors presented the concept of "focus area maturity

S36, maturity models are an established tool for identifying strengths and weaknesses of certain domains. Having built this maturity model for Business Intelligence (BI) in previous research, the authors explored the influence of contextual factors on the evolution of BI maturity. media.

S37, this paper developed a maturity model for the social adoption of social

S39 this paper presented a case study involving 129 hospitals in Switzerland applying a maturity model that was derived mathematically. 
The following part of this paper describes in greater detail the result of the systematic mapping research questions.

\subsection{RQ 01: What are the approaches and design structures for specifying a maturity model?}

The findings from these studies suggest that there are some dominant approaches to maturity model specification support: normative theories, best practices or certification mechanisms and benchmarking tools. One criticism in much of the literature on this question is the difficulty in determining which approach was used to specify the model. These approaches determine the purpose and goals of use, as well as the motivation to develop maturity models:

- Normative theories that are predominantly grounded as process theories. The events occur in a sequence of time, becoming mature towards the best. Events occur around a first entity, such as a company. Most models use this structure, even if indirectly [Damsgaard and Scheepers 1999] [Nolan and Gibson 1974] [Renken 2004].

- Best practice guide or certification mechanism are based on actual practices and reflect the best of the state of the practice. They organize the practices, which are already considered effective, in a structure that aims to help the organization establish priorities for improvement and also provides a guide for the implementation of these improvements. For example, Capability Maturity Model (CMM) [CMMI 2010] [De Bruin 2005] [Fiss 2011].

○ Benchmarking: The third and final worldview portrays a maturity model as a practice, wherein organizations are classified and compared against each other using a scale from low to high maturity [Luftman 2000] [Raber, Wortmann and Winter 2013].

Figure 5 shows these approaches. We noted that fewer than $22 \%$ of the papers included in this study cited their approaches.

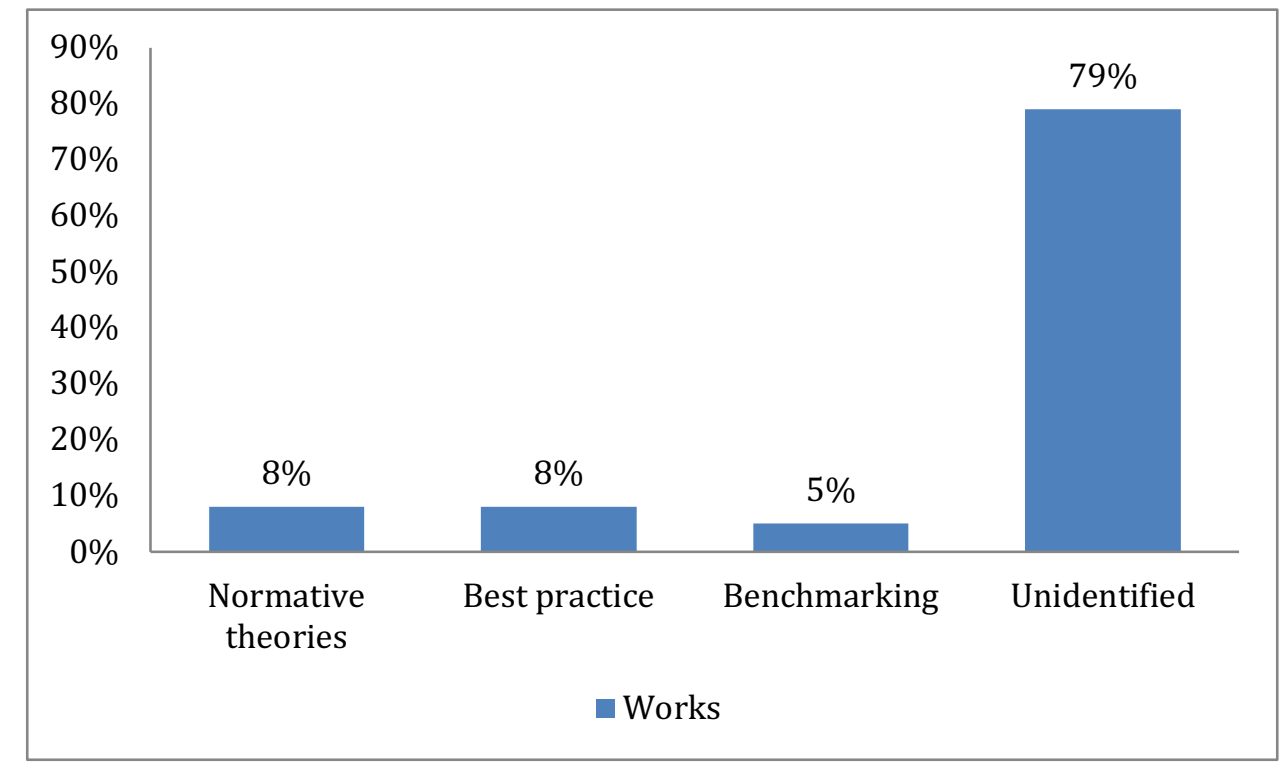

Figure 5. Approaches 
Frequently, the terms fixed-stage or continuous-stage have been used to classify a maturity model [Van Steenbergen 2013]. This classification is challenging to define because it depends on numerous factors, such as model scope, abstraction level, and other characteristics. The purpose of maturity models is to outline the path to maturation, including the stages definition and the relationship between these stages [Röglinger, Pöppelbuß and Becker 2012]. The premise of these models is that a higher grade or maturity score also means a positive change in several dimensions, which provides a construct for measuring progression. Three design structures can be adopted:

- Nolan's Stage of Growth Model: Model of the growth stages (initially created and applied in Data Processing Company). Through studies conducted in a series of companies, Nolan suggested that businesses evolve into six stages of growth of the data processing function. Most of the models present a maturity scale ranging from 3 to 6 levels and are differentiated by the method used to calculate the result of maturity levels, evaluated dimensions, and contents of each level [Nolan and Gibson 1974].

- Crosby's Grid: In the model proposed by Crosby, five successive stages of quality maturation are established: uncertainty, awakening, enlightenment, wisdom, and certainty. As with Nolan's, the maturity scale can range from 3 to 6 levels [Crosby 1980].

○ Capability Maturity Model (CMM): It can be defined as being the "best practices" for diagnosis and evaluation of maturity in software development. "CMM" should not be understood as a methodology, because the "CMM" does not say exactly how to do, but rather what should be done (best practices) [CMMI 2010].

\subsection{SRQ: What are the characteristics and definitions to use while developing maturity models?}

In systematic mapping, no data was found on scientific or systematic processes to develop maturity models, so there are gaps in this area. Five important concepts have been identified to compose a maturity model:

- Maturity levels: Also known as stages, levels, maturity score, etc. used to describe the general abstract or maturity of the entity and the level of abstraction at the highest level.

- Dimensions: Also called as reference variables, process areas, capacity, and critical success factors;

- Subcategories: These are second-level variables of which the dimensions depend;

- Path to Maturity: Most of the revised models follow a linear, unidirectional path, of lesser maturity to the greatest;

○ Evaluation issues: which are usually directly linked to subcategories, such as maturity score or level, generally viewed as a graphical representation. 
Table 6. Vocabulary and guidelines

\begin{tabular}{|c|c|c|c|}
\hline Concept & Categories & Characteristics & References \\
\hline \multirow{2}{*}{ 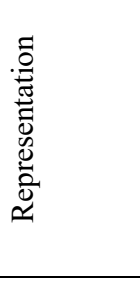 } & Composition & $\begin{array}{l}\text { Stage of growth model; Focus area model; } \\
\text { CMM-like; Maturity Matrix or grids. }\end{array}$ & $\begin{array}{l}\text { [[S7] Damsgaard and Scheepers, } \\
\text { 1999]. [Spruit and Röling, 2014], } \\
\text { [S24 Mettler, Rohner and Winter } \\
\text { 2010] }\end{array}$ \\
\hline & $\begin{array}{c}\text { Path of } \\
\text { maturation }\end{array}$ & $\begin{array}{l}\text { Most of the reviewed models follow a } \\
\text { linear, unidirectional path from lower } \\
\text { maturity to higher maturity. }\end{array}$ & $\begin{array}{l}\text { [S17 Davenport et al. 2007], [S1 } \\
\text { Nolan and Gibson 1974] }\end{array}$ \\
\hline \multirow[t]{4}{*}{ 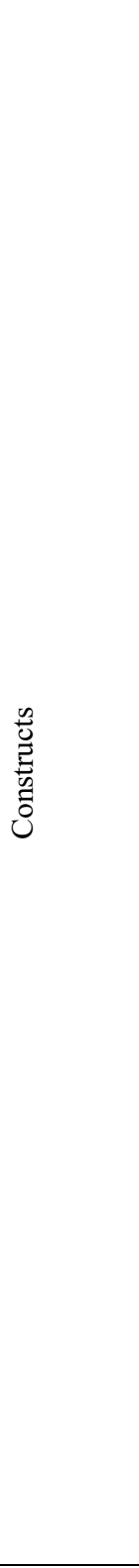 } & $\begin{array}{c}\text { Representation } \\
\text { of Maturity }\end{array}$ & $\begin{array}{l}\text { 1. Level: Higher the level of } \\
\text { abstraction lowers the number of } \\
\text { dimensions. } \\
\text { 2. Stages or levels: around } 3 \text { to } 6 \text {, } \\
\text { depending on the model and its } \\
\text { purpose. E.g., Crosby grid (5), } \\
\text { Nolan (4), CMM (5), and many } \\
\text { more. } \\
\text { 3. Stage fixed or Continuous: } \\
\text { Continuous models allow scoring } \\
\text { of characteristics at different } \\
\text { levels; staged models require that } \\
\text { all elements of one distinct level } \\
\text { are achieved. } \\
\text { Numeric Value: Maturity score } \\
\text { depicted using numbers. Purpose } \\
\text { of use is comparative, i.e., } \\
\text { benchmarking. Type } 1 \text { - Focus } \\
\text { area maturity models (less } \\
\text { popular). Type } 2 \text { - HSRM model } \\
\text { and IS/ICT capability framework } \\
\text { depict benchmark } \\
\text { variables/dimensions (More } \\
\text { popular). } \\
\text { Purpose of use: Descriptive, } \\
\text { prescriptive, comparative or a } \\
\text { combination. }\end{array}$ & $\begin{array}{l}\text { [S12 and S15 De Bruin et al., } \\
\text { 2005], [S2 Crosby 1980], [S1 } \\
\text { Nolan and Gibson 1974], [S16 } \\
\text { Paulk et al., 2006], [S36 Raber, } \\
\text { Wortmann and Winter 2012], [S21 } \\
\text { CMMI 2010], [Spruit and Röling, } \\
\text { 2014], [S35 Van Steenbergen et al. } \\
\text { 2011], [S10 Renken 2004], [S20 } \\
\text { Röglinger, Pöppelbuß and Becker } \\
\text { 2012], [S36 Mettler, Rohner and } \\
\text { Winter 2010] }\end{array}$ \\
\hline & Maturity levels & $\begin{array}{l}\text { Levels are archetypal states of maturity of } \\
\text { the object that is assessed. Each level } \\
\text { should have a set of distinct characteristics } \\
\text { that are empirically testable. }\end{array}$ & $\begin{array}{l}\text { [S1 Nolan and Gibson 1974], [S36 } \\
\text { Raber, Wortmann and Winter } \\
\text { 2012] }\end{array}$ \\
\hline & Dimensions & $\begin{array}{l}\text { Also termed Benchmark variables, process } \\
\text { areas, Capability, and critical success } \\
\text { factors. Cognitive capacity of users - } \\
\text { "Humans have limited cognitive capacities } \\
\text { for memory, attention, and perception." } \\
\text { Hence limit first level dimensions from } 5 \text { to } \\
7 \text {. }\end{array}$ & $\begin{array}{l}\text { [S24 Mettler, Rohner and Winter } \\
\text { 2010], [Karkkainen, Jussila and } \\
\text { Lyytikkä 2011] }\end{array}$ \\
\hline & Sub-categories & $\begin{array}{l}\text { Second level variables on which the } \\
\text { dimensions depend. E.g., BPMM with } 30 \\
\begin{array}{l}\text { subcategories. DyAMM with } 16 \\
\text { dimensions. }\end{array}\end{array}$ & $\begin{array}{l}\text { [S12 and S15 De Bruin et al., } \\
\text { 2005], [S35 Van Steenbergen et al. } \\
\text { 2011] }\end{array}$ \\
\hline 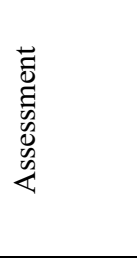 & Instantiation & $\begin{array}{l}\text { Self-assessment via Surveys is the most } \\
\text { widely adopted instruments. Instantiation is } \\
\text { mostly through web-based software tool or } \\
\text { an Excel file. Third party assessment or } \\
\text { certifications are other techniques applied } \\
\text { in this case. E.g., CMM assessments are } \\
\text { done by well trained and certified experts. }\end{array}$ & $\begin{array}{l}\text { [S12 and S15 De Bruin et al., } \\
\text { 2005], [S32 Wendler 2012], [S24 } \\
\text { Mettler, Rohner and Winter 2010], } \\
\text { [S16 Paulk et al. 2006], }\end{array}$ \\
\hline
\end{tabular}


The generic structure of a maturity model can be divided into two parts.

○ The first part depicts the generic design structure of maturity models comprising the different stages each with different dimensions and sub-categories.

○ The second part depicts the hierarchical relationships between the typical components of the maturity model.

The table below illustrates the vocabulary and guidelines while designing and developing constructs.

\subsection{SRQ: What are the types and generic methods for developing maturity model?}

We classified maturity models found in papers depending on the construction of dimensions and levels, wherein process of deriving constructs is classified as (i) conceptual, generic or specific with theoretical foundation; (ii) qualitative, built using case studies, interviews, focus groups, etc. (iii) quantitative, built using techniques (e.g., survey followed by Factor analysis, Rasch analysis, etc. (iv) derivative, generic or specific without a theoretical foundation.

o Conceptual: Maturity models that use a theoretical approach to deriving dimensions. A strong theoretical basis is needed, for example, the intranet model [Damsgaard and Scheepers 1999]. In the intranet model, dimensions were determined based on studies of critical success factors in the intranet domain.

- Qualitative: Models that predominantly use a qualitative empirical approach to deriving dimensions and levels are classified in this category. A literature study is usually followed up by a conceptual maturity model, which is then verified and tested through focus groups, Delphi methods and/or interviews before operationalizing. For example, BI (business intelligence) maturity model [Raber, Wortmann and Winter 2013]. In the BI maturity model, the dimensions were determined through a questionnaire that identifies the process areas.

- Quantitative: Models that predominantly use the quantitative approach to deriving dimensions and levels are classified in this category. Use of the Rasch algorithm-based approach is the most common. For example, process management in hospital [Cleven et al., 2014]. In this example, the dimensions were determined through key processes.

○ Derivative: In these category models that predominantly use prior published maturity model literature and fit related domain problems into the structure without strong theoretical or empirical foundations are classified - for example, Business-IT Alignment Maturity [Luftman, 2000].

Figure 6 shows these types of maturity models found in the papers. Most of the models analyzed in this study were predominantly conceptual when it comes to deriving dimensions and maturity levels. Most of the literature has been conceptual and /or derivative and empirical validation could increase the rigor of maturity models.

In our study, thirteen maturity models were found. The table below illustrates the Classification of Methods and Instruments while designing and developing constructs. 


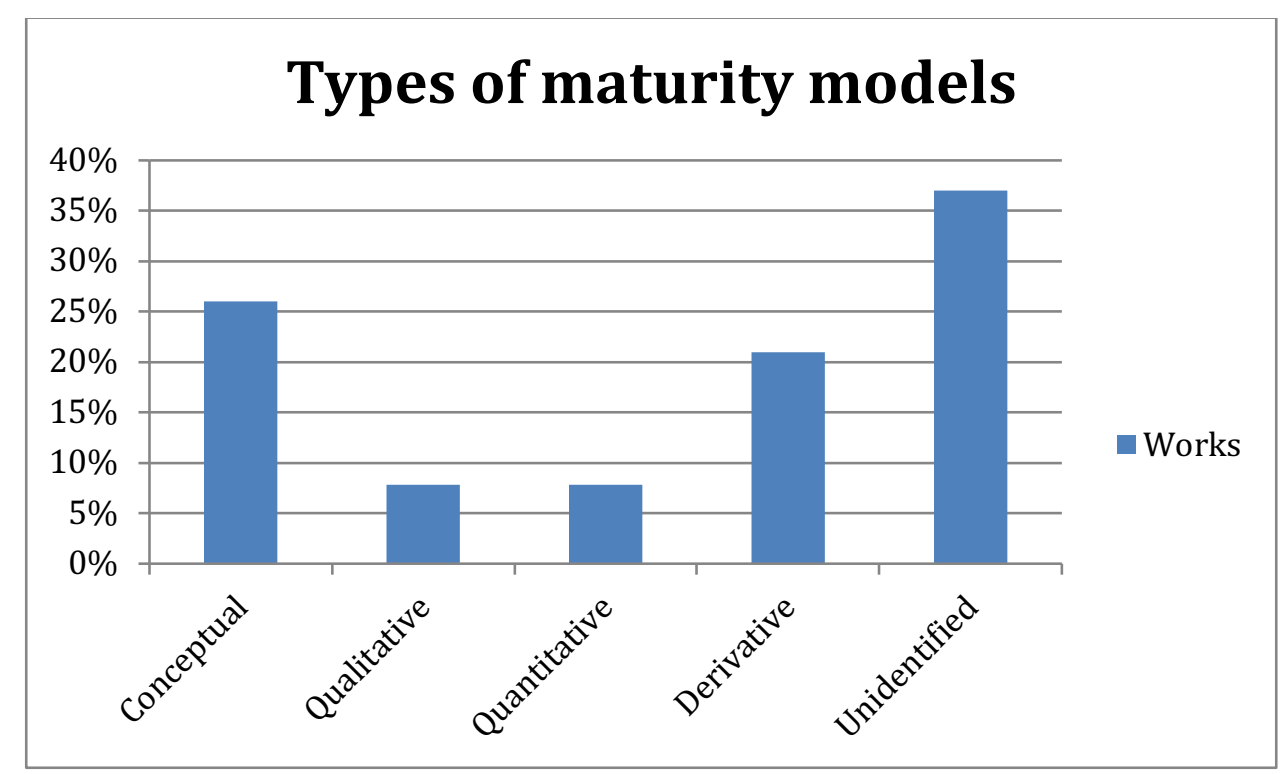

Figure 6. Types of maturity models

\subsection{SRQ: What are the theoretical considerations that help while developing maturity models?}

It becomes clear that the main criticism of maturity models is the lack of theoretical bases for determining the path of maturity and evolution in stages [Van De and Poole 1995]. In order to address this criticism, a process theory can be employed to substantiate the path to maturity and stages. Process theories are classified into four classes: life cycle, evolution, dialectic, and teleology, and some of these theories could be used to conceptualize maturity [Plattfaut et al. 2011].

According to [Van De and Poole 1995], these theories can be described in the following manner:

- Life cycle: Organic growth with an entity that develops from its initiation into the final state. The path of change is imminent for the entity, primarily a unitary, cumulative and conjunctiva sequence. The event progression is irreversible and linear, and the driving force usually comes from within the entity.

- Evolution: They employ the mechanism of "competitive survival" to explain the evolution of the species. Thus, the entities compete with similar entities for resources. The progression of the event is recurrent, cumulative and probabilistic (of variation, selection, and retention).

○ Dialectic: Conflict theory as a motive force, while teleology follows the logic of establishing goals towards an imagined state.

We believe that the use of these theories can be a way to minimize the criticisms related to the lack of theoretical considerations, as is also defended by [Plattfaut et al. 2011].

Figure 7 shows these process theories recognized in the maturity models found in the papers. 
Table 7. Methods and Instruments while designing and developing constructs

\begin{tabular}{|c|c|c|c|c|c|}
\hline 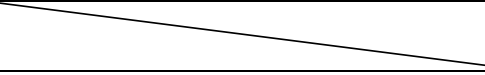 & \multicolumn{4}{|c|}{ Instrument } & \\
\hline Approach /Model & 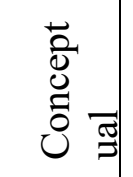 & 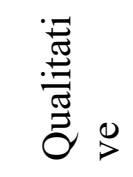 & 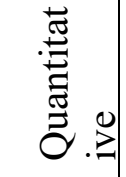 & 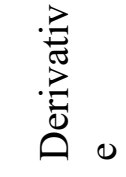 & References \\
\hline Intranet Model & $\bullet$ & $\bullet$ & & & $\begin{array}{lr}\text { [S7 } & \text { Damsgaard } \\
\text { and } & \text { Scheepers } \\
1999] & \\
\end{array}$ \\
\hline Analytics Maturity & $\bullet$ & & & & $\begin{array}{l}\text { [S17 Davenport et } \\
\text { al 2007] }\end{array}$ \\
\hline Business-IT alignment & $\bullet$ & & & $\bullet$ & $\begin{array}{l}{[S 8 \text { Luftman, }} \\
2000]\end{array}$ \\
\hline Social media Business & $\bullet$ & & & $\bullet$ & $\begin{array}{l}\text { [S33 Duane and } \\
\text { OReilly 2012] }\end{array}$ \\
\hline DyAMM & $\bullet$ & & & $\bullet$ & $\begin{array}{l}{[\text { S35 Van }} \\
\text { Steenbergen et al. } \\
2013]\end{array}$ \\
\hline BI maturity model & $\bullet$ & & $\bullet$ & $\bullet$ & $\begin{array}{l}\text { [Lahrmann et al. } \\
\text { 2011] }\end{array}$ \\
\hline BI maturity model & $\bullet$ & $\bullet$ & $\bullet$ & & $\begin{array}{l}{[\text { S24 Mettler, }} \\
\text { Rohner } \\
\text { Winter 2010] }\end{array}$ \\
\hline $\begin{array}{l}\text { Business } \\
\text { Intelligence Maturity }\end{array}$ & $\bullet$ & & & & $\begin{array}{l}{[\text { S36 Raber, }} \\
\text { Wortmann and } \\
\text { Winter 2013] }\end{array}$ \\
\hline Capability Maturity Model & $\bullet$ & & & $\bullet$ & $\begin{array}{l}\text { [S16 Paulk et al. } \\
\text { 2006] }\end{array}$ \\
\hline $\begin{array}{l}\text { Process Management in } \\
\text { Hospitals }\end{array}$ & $\bullet$ & $\bullet$ & • & & $\begin{array}{l}\text { [S39 Cleven et al., } \\
\text { 2014] }\end{array}$ \\
\hline Consumer Cloud Maturity & & & & $\bullet$ & [Weiss et al, 2013] \\
\hline Social media Innovation & & & & $\bullet$ & $\begin{array}{l}\text { [S37 Lehmkuhl, } \\
\text { Baumol and Jung } \\
\text { 2013] }\end{array}$ \\
\hline $\mathrm{BI}$ & & & & & [Dinter, 2012] \\
\hline
\end{tabular}




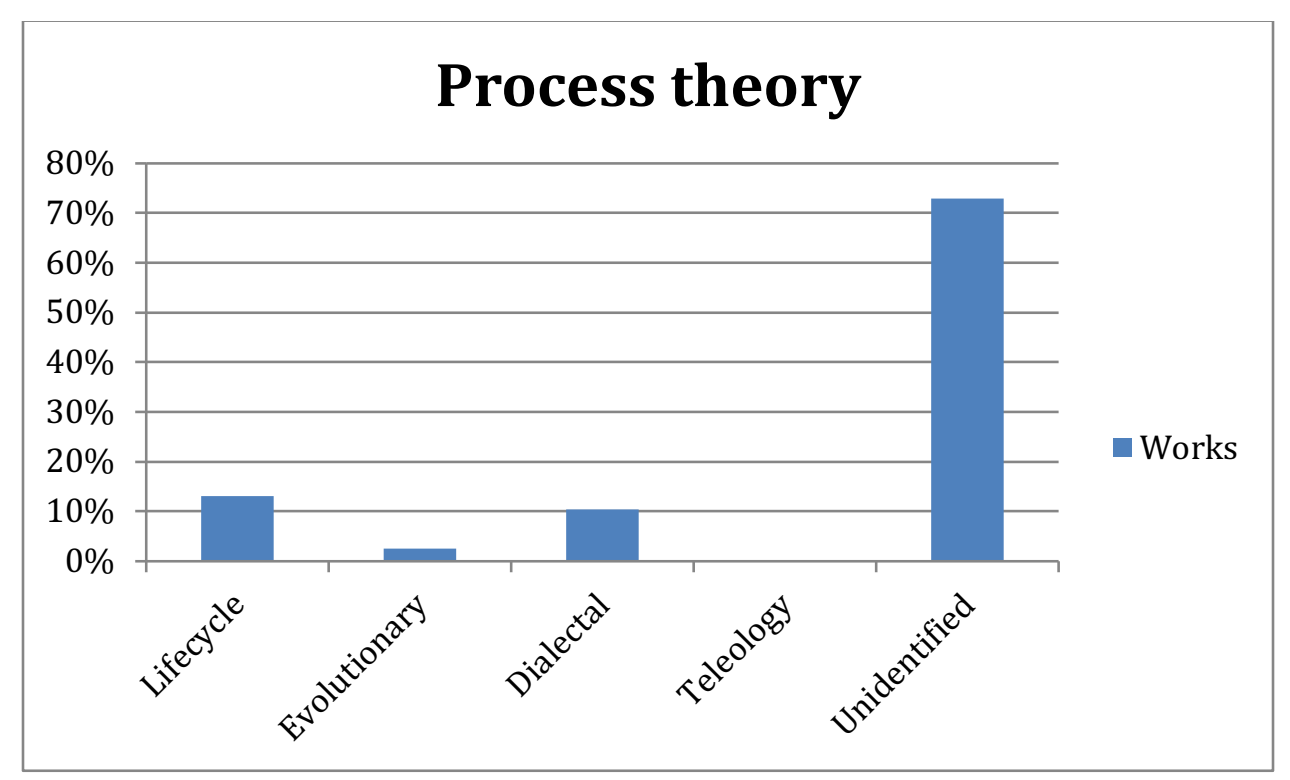

Figure 7. Process theory

A compilation of the maturity models found and their corresponding Instruments while designing and developing constructs with process theory can be found in Table 8 .

Table 8. Maturity models viewed through the lens of process theory

\begin{tabular}{|c|c|c|c|c|c|}
\hline-2 & \multicolumn{4}{|c|}{ Process theory } & 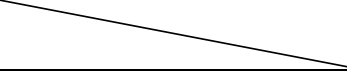 \\
\hline Approach /Model & 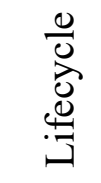 & 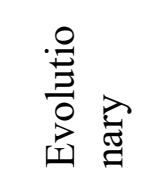 & 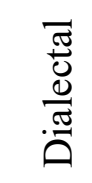 & $\begin{array}{l}\frac{\infty}{0} \\
\frac{0}{0} \\
\frac{0}{0} \\
\stackrel{0}{\oplus}\end{array}$ & References \\
\hline Intranet Model & $\bullet$ & & $\bullet$ & & $\begin{array}{lr}{[S 7} & \text { Damsgaard } \\
\text { and } & \text { Scheepers } \\
1999] & \\
\end{array}$ \\
\hline Analytics Maturity & $\bullet$ & $\bullet$ & $\bullet$ & & $\begin{array}{l}\text { [S17 Davenport et } \\
\text { al 2007] }\end{array}$ \\
\hline Business-IT alignment & $\bullet$ & & $\bullet$ & & $\begin{array}{l}{[S 8 \text { Luftman, }} \\
2000]\end{array}$ \\
\hline Social media Business & • & & $\bullet$ & & $\begin{array}{l}\text { [S33 Duane and } \\
\text { OReilly 2012] }\end{array}$ \\
\hline DyAMM & $\bullet$ & & & & $\begin{array}{l}{[\text { S35 Van }} \\
\text { Steenbergen et al. } \\
\text { 2013] }\end{array}$ \\
\hline
\end{tabular}




\subsection{RQ 02: What are the evaluation and validation methods applied in maturity model?}

In [Wendler 2012] 237 articles were studied, extracting maturity models and categorizing them as conceptual and design oriented. A gap in the evaluation and validation of the models was identified. Moreover, similar to many other authors in the past, Wendler also questioned the "rigor" of maturity models, stating that only 7 of the 105 maturity models used empirical methods (qualitative or quantitative) for their construction. The empirical validations of these models are scarce, and the authors usually continue to operationalize the model (i.e., survey or controlled experiments). The mapping results, $18 \%$ of the papers were evaluated through interviews, $33 \%$ evaluated through a survey and $49 \%$ evaluated through a case study.

Almost half of the published articles only present the conceptual design of maturity models. Authors often present the maturity model and its development process, but no (empirical) validation is shown. Surprisingly few papers reported that the developed maturity models should undergo any (empirical) evaluation. A small minority of the conceptual articles introduced maturity models only as a byproduct, besides other contributions. Surveys were predominant for validating maturity models. $8 \%$ used a third party method. Furthermore, $3 \%$ used certification as a method. The construction and specification of maturity models, without empirical validation, are a weakness.

Figure 8 shows the evaluation and validation methods that were recognized in the maturity models found in the papers.

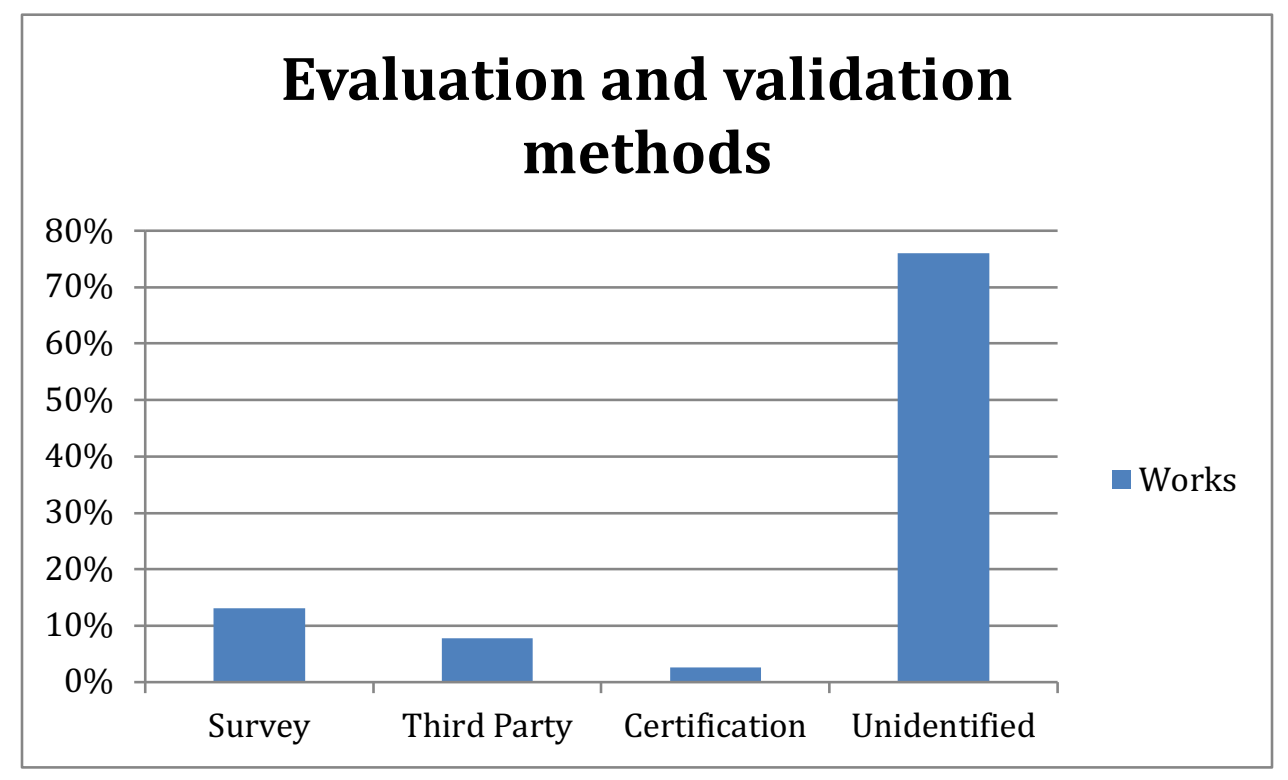

Figure 8. Evaluation and validation methods

A compilation of the maturity models found and their corresponding Instruments for evaluation can be found in Table 9.

\subsection{Discussion}

This chapter summarizes results and related considerations. Mapping findings can be summarized in five points (i) The high rate of conceptual maturity models is evident when it comes to deriving dimensions and maturity levels; (ii) Empirical validations are 
scarce. (iii) Qualitative methods are used more than quantitative ones at the development stage. (iv) Quantitative methods are less widely used although there are approaches based on the Rasch algorithm; (v) Finally, many papers have recently cited a design-oriented approach (rather than behavioral approaches) when developing a maturity model.

Table 9. Methods and Instruments (of evaluation) while designing and developing constructs

\begin{tabular}{|c|c|c|c|c|c|}
\hline 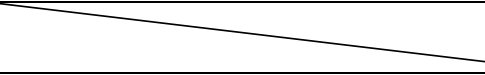 & Instr & ent & & & \\
\hline Approach /Model & 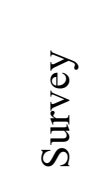 & 总 尝 & 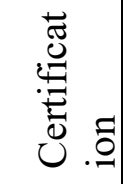 & $\begin{array}{l}\ddot{0} \\
\dot{Z}\end{array}$ & References \\
\hline Intranet Model & & & & $\bullet$ & $\begin{array}{l}\text { [S7 Damsgaard and } \\
\text { Scheepers 1999] }\end{array}$ \\
\hline Analytics Maturity & & & & $\bullet$ & $\begin{array}{l}\text { [S17 Davenport et } \\
\text { al. 2007] }\end{array}$ \\
\hline Business-IT alignment & $\bullet$ & $\bullet$ & & & [S8 Luftman, 2000] \\
\hline Social media Business & & & & $\bullet$ & $\begin{array}{ll}{[\text { S33 Duane and }} \\
\text { OReilly 2012] }\end{array}$ \\
\hline DyAMM & • & & & & $\begin{array}{l}{[\mathrm{S} 35} \\
\text { Steenbergen et al. } \\
2013]\end{array}$ \\
\hline BI maturity model & & $\bullet$ & & & $\begin{array}{l}\text { [Lahrmann et al. } \\
\text { 2011] }\end{array}$ \\
\hline BI maturity model & & $\bullet$ & & & $\begin{array}{l}{[S 24 \text { Mettler, }} \\
\text { Rohner and Winter } \\
\text { 2010] }\end{array}$ \\
\hline $\begin{array}{l}\text { Business } \\
\text { Intelligence Maturity }\end{array}$ & $\bullet$ & & & & $\begin{array}{lr}{[\text { S36 }} & \text { Raber, } \\
\text { Wortmann } & \text { and } \\
\text { Winter 2013] } & \end{array}$ \\
\hline Capability Maturity Model & & & $\bullet$ & & $\begin{array}{l}\text { [S16 Paulk et al. } \\
\text { 2006] }\end{array}$ \\
\hline $\begin{array}{l}\text { Process Management in } \\
\text { Hospitals }\end{array}$ & $\bullet$ & & & & $\begin{array}{l}\text { [S39 Cleven et al. } \\
\text { 2014] }\end{array}$ \\
\hline Consumer Cloud Maturity & & & & $\bullet$ & [Weiss et al. 2013] \\
\hline Social media Innovation & & & & $\bullet$ & $\begin{array}{l}{[\text { S37 Lehmkuhl, }} \\
\text { Baumol and Jung } \\
\text { 2013] }\end{array}$ \\
\hline $\mathrm{BI}$ & $\bullet$ & & & & [Dinter, 2012] \\
\hline
\end{tabular}


Related to maturity models structures, the literature highlighted four main challenges to the creation of an instrument to measure maturity: (i) how to measure the distance between maturity levels; (ii) what is the scale of measurement; (iii) how to solve the challenge of additivity and calculate global maturity; (iv) origin of dimensions.

Developing maturity models is still challenging. Some papers focused on development (guidelines) of new maturity models, such as in [Back and Haager 2011], [de Bruin 2005] and [Duane and OReilly 2012] proposing guidelines. However, there was a significant effort by some researchers to standardize the development of the maturity model and research through prescriptive guidelines, standardized vocabulary and validated the procedure. The focus area model [Van Steenbergen et al. 2013] adopts the design science paradigm, while [de Bruin et al. 2005] propose a 6-stage development model, together with the concept of layers and a scheme to define characteristics. [Becker, Knackstedt and Pöppelbuß 2009] proposes an eight-step model based on scientific design guidelines (design Science guidelines). Furthermore, [SolliSæther and Gottschalk 2010] propose a modeling process for stage-based maturity models, while at the same time theorizing clearly on the core topics of growth stages.

Very little was found in the literature on the question of maturity model development. Some proposals defend a sequential iterative step-by-step approach to developing a maturity model. Also, the approaches emphasize implementation and validation to ensure practical relevance. There are three proposals for the development of a maturity model: (i) approach divided into six stages (scope, design, populate, deploy and maintain) [De Bruin 2005]; (ii) approach divided into eight stages (Problem definition, Study existing models, Design strategy, Iterative development process, Transfer concept \& evaluation, Implementation of transfer media, Evaluation of results and Iterative continuation) [Becker, Knackstedt and Pöppelbuß 2009]; (iii) finally, approach divided into five stages (Suggested stage model, Conceptual model, Theoretical model, Empirical model and Revised stage model) [Solli-Sæther and Gottschalk 2010].

Additionally, [Mettler, Rohner and Winter 2010] identified two approaches to constructing a model: (i) top-down, initially defining the maturity stages and then creating the dimensions. Then adjusting the measurements and settings; (ii) bottom-up, requirements and measures are determined, with definitions of stages later. Commonly, the first approach works for a domain with little evidence of what maturity is for the company. In a well-established domain, the focus would be on how to measure maturity instead of what it stands for, thus requiring the second approach.

Therefore, it can be concluded that there are no rigid rules for deciding the approach to developing a model, but it is important to use existing literature to validate dimensions and development.

Maturity models have been immersed in criticism, according to [King and Kraemer 1984], questioning the lack of empirical validity, mistaken structural assumptions and being too simplistic to be helpful. Some criticisms can be found in relation to the development approaches of maturity models: (i) absence of theoretical justification for models followed; (ii) lack of empirical validation in the selection of dimensions; (iii) absence of operationalization of measurement of maturity (very conceptual). Maturity models since the publication of [Nolan and Gibson 1974] have 
mostly adopted a lifecycle based on stages or an evolutionary approach, while describing the pathways of the entities to maturity. We have discovered that there is a difficulty in finding a suitable maturity model that has been validated in the literature. One of the reasons for this could be the lack of theoretical considerations during the development of the model and the lack of a standard vocabulary for the description of the model.

In this context and analysis, we propose the following recommendations to be adopted by the developers of maturity models:

- Use any of the three approaches/paradigms for developing the maturity model. Even though the steps are not necessarily in sequential order, it is important to document the approach, as this will help to achieve standardization.

○ Use well-formulated process theories, theoretical approaches, or both, while conceptualizing and presenting the path to maturity, in addition to establishing precise definitions of maturity, facing theoretical challenges and enabling theoretical interpretation.

- Employ empirical methods in model development and improve efforts to validate existing and new maturity models before dissemination.

- Use vocabulary and guidelines during the development phase and in the dissemination phase (publication) of maturity models.

There is an opportunity for future research into applying empirical methods to construct maturity models and measure maturity itself.

In this paper, we have explored maturity models, their structure, and standardization, as well as the processes for their development and evaluation. As conclusions:

○ Most maturity models can be described using a generic structure.

○ There are three paradigms of maturity models: normative theories, best practice guidelines, and benchmarking tools.

○ The path to maturation (i.e. something better, more advanced, higher) is always linear, advancing (rarely returning), in which the entity improves considerably in terms of desired results, i.e. capabilities, value creation, performance, etc. The notion of equifinality has not been recognized until now.

- Researchers have recently used the design science approach to develop maturity models. Design science is fundamentally a troubleshooting paradigm that seeks to create innovations that define ideas, practices, technical capabilities and products through which analysis, design, implementation, management and use of information systems are effective and efficiently attained.

- Most maturity models are predominantly conceptual. It is rare to encounter maturity models that use theoretical, causal approaches or hypothesis testing.

- There is a need for emphasis on empirically derived dimensions, as well as validation of maturity levels. 


\section{Limitations and threats to validity}

Our systematic mapping considered four digital databases: ACM, IEEE Explore, Springer, and Basket of eight journals, as well as manual searching. Despite our efforts, some important papers may have been left out. Although the bases of analysis are reliable, this is a threat to validity in relation to generalization. There could also be some bias in the mapping. To reduce this in the selection of papers, we follow a protocol indicating how the mapping was to be done. Although we carried out a systematic process, some potential threats could limit the validity of our results, the most important of which are listed below

The first threat is related to the coverage of the existing literature. It is difficult to be exhaustive about all the published work on maturity models for concrete problems. To maximize the coverage, we selected Springer, one of the most exhaustive publication databases. Even if we cannot guarantee full coverage of the published material, our sample is large and representative enough to produce trustworthy results.

The second potential limitation is the in encoding the scope of the study in a query. Indeed, there are no consensual terms to refer to concrete maturity model proposals. To avoid missing a relevant paper, we opted for a generic query, which includes "maturity model" and its variants, such as capability and improvement. This, however, increased the number of paper to screen.

The third potential threat to the validity of our study is related to the impact of the exclusion criteria. Because we are studying maturity models as main research contributions, we only focused on long papers from the main research forums and neglected other contributions, such as technical reports. The second impact of the exclusion criteria is the potential subjectivity of the decision of whether a maturity model is the main contribution of a paper. One of the reviewers worked with a more relaxed interpretation of this criterion, which produced most of the conflicting results. All these conflicts were resolved at face to face meetings and did not require the intervention of another reviewer.

\section{Conclusion and future work}

There is a strong belief among researchers that better processes, as described in a maturity model, also mean better or higher results or performance. Although this assumption seems correct, according to [Mullaly 2014], there was minimal evidence in the literature that improvements along the maturation path also correspond to the incremental value derived. Mostly, the score and the stage of "maturity" or level is an artificial or speculative measure used only for comparative evaluation, which means nothing when used in comparative sense [Andersen and Hendrickson 2006].

Finally, most studies on maturity models of [Nolan and Gibson 1974], [Crosby 1980] and [Winkler et al. 2015] fight for the linear path to maturity, ignoring the notion of equifinality that, in the words of [El Sawy et al. 2010], means that an entity or system can achieve the same result of different initial conditions and through many different paths. Therefore, developers of maturity models should analyze the configurable sectoral theory approach advocated by [El Sawy et al. 2010] and [Fiss 2011] to conceptualize maturity, because it assumes complex causality and nonlinear relationships, thus addressing many of the criticisms in the literature. 
Throughout this study, we have identified gaps in the research and planned to address them in future work. Firstly, we plan to address the notion of equifinality when designing maturity models and the path to maturity. The fuzzy proposals of [El Sawy et al. 2010] and [Fiss 2011] will be analyzed in detail. Secondly, we will probably explore the phases before the decision to create a maturity model, through interviews with model developers in the practical, academic and consulting context. At the same time criteria for which a maturity model can be regarded as successful or not could be identified. Finally, we plan to develop, validate and implement a maturity model using all the recommendations proposed in this paper.

In addition, we believe that the concept of a linear path for maturation is not the most effective and not recognizing the notion of equifinality is also an important critique that needs to be addressed. Few models have recognized and implemented these challenges.

The literature mapping in this paper has opened the gates for further exploration, and we encourage the community to join our efforts to qualify and further the researchbased knowledge and engagement in practitioner-oriented development and use of maturity models. The technology momentum from social media and new data analysis techniques have the potential to turn the concept of involvement in system development up-side-down and suggest new routes for researchers to follow.

The present study has gone some way towards enhancing our understanding of maturity model construction and evaluation and its limitations. In future investigations, it might be possible to use a different approach to the development of a maturity model in other fields of research.

\section{Acknowledgments}

The authors thank Capes (Coordination for the Improvement of Higher Education Personnel, Brazil) for the financial support, and UFBA (Federal University of Bahia, Brazil) for supporting and funding one of the authors.

\section{References}

Andersen, K. V. and H. Z. Henriksen (2006). "E-Government Maturity Models: Extension of the Layne and Lee Model". Government Information Quarterly, 23(2), pp. 236-248.

Associação Brasileira de Normas Técnicas - ABNT. (2010). NBR ISO 9004: Gestão para o sucesso sustentado de uma organização: uma abordagem da gestão da qualidade. Rio de Janeiro: ABNT.

Anza, F. A.; Sensuse, D. I. and Ramadhan, A. Developing E-government maturity framework based on COBIT 5 and implementing in city level: Case study Depok city and South Tangerang city. Proc. Computer Science and Informatics (EECSI) 2017 4th Int. Conf. Electrical Engineering, 2017, 1-6

Back, A. and C. Haager (2011). "Assessing Degrees of Web-2.0-ness for Websites: Model and Results for Product Websites in the Pharmaceutical Industry." BLED 2011. Paper 48. 
Becker, J., B. Niehaves, J. Poeppelbuss and A. Simons (2010). "Maturity Models in IS Research." ECIS 2010, Paper 42.

Becker, J., R. Knackstedt and J. Pöppelbuß (2009). "Developing Maturity Models for IT Management." Business \& Information Systems Engineering 1(3): 213-222.

Bemowski, K. (1996). Baldrige award celebrates its 10th birthday with a new look. Quality Progress, 29(12), 49.

Bessant, J., Caffyn, S., \& Gallagher, M. (2001). An evolutionary model of continuous improvement behavior. Technovation, 21(2), 67-77.

Carvalho, J. V.; Rocha, Á.; Abreu, A. and Afonso, A. Development methodology of the HISMM Maturity Model. Proc. 12th Iberian Conf. Information Systems and Technologies (CISTI), 2017, 1-7

Carvalho, J. V., Pereira, R. H., \& Rocha, A. (2018, June). Maturity models of education information systems and technologies: a systematic literature review. In 2018 13th Iberian Conference on Information Systems and Technologies (CISTI) (pp. 1-7). IEEE.

Carvalho, J. V., Rocha, A., Vasconcelos, J., Abreu, A. A health data analytics maturity model for hospitals information systems. International Journal of Information Management, 2018.

Cleven, A., R. Winter, F. Wortmann and T. Mettler (2014). "Process management in hospitals: an empirically grounded maturity model." Business Research 7(2): 191216.

CMMI , P. T. (2010). "CMMI for Development, Version 1.3 (CMU/SEI-2010-TR-033) ". Software Engineering Institute, Carnegie Mellon University, 2010. http://resources.sei.cmu.edu/library/asset-view.cfm?AssetID=9661 (Access in 15 de May, 2017).

Cosic, R., G. Shanks, S. Maynard and J. Lamp (2012). "Towards a business analytics capability maturity model." Australasian Conference on Information Systems 2012, pp. 1-11.

Correia, E., Carvalho, H., Azevedo, S., \& Govindan, K. (2017). Maturity models in supply chain sustainability: A systematic literature review. Sustainability, 9(1), 64.

Crosby, P. B. (1980). Quality Is Free: The Art of Making Quality Certain, New York, NY: Mentor.

Chrissis, M. B.; Konrad, M.; Shrum, S. CMMI®: guidelines for process integration and product improvement. Addison Wesley, 2003.

Damsgaard, J. and R. Scheepers (1999). "Managing the crises in intranet implementation: a stage model." Information Systems Journal 10(2): 131-149.

Davenport, T., H and J. Harris, G. (2007). "Competing on Analytics: The New Science of Winning", Massachusetts: Harvard Business School Press.

De Bruin, T., M. Rosemann, D. Bartmann, F. Rajola, J. Kallinikos, D. Avison, R. Winter, P. Ein-Dor, J. Becker, F. Bodendorf and C. Weinhardt (2005). "Towards a 
Business Process Management Maturity Model." Australasian Conference on Information Systems 2005.

De Bruin, T., R. Freeze, U. Kaulkarni, M. Rosemann, B. Campbell, J. Underwood and D. Bunker (2005). "Understanding the Main Phases of Developing a Maturity Assessment Model." Australasian Conference on Information Systems 2005.

Delloitte-eCommerce-Assessment (2012). "European eCommerce Assessment 2012 Benchmarking the top 200 in online retail." https://www2.deloitte.com/content/dam/Deloitte/nl/Documents/consumerbusiness/deloitte-nl-european-ecommerce-assessment-2012.pdf. (Access in 15 de May, 2017).

DELTA-Model-Accenture (2013) "The Accenture Netherlands Analytics DELTA Survey 2013" http://www.it-executive.nl/images/uploads/downloads/accentureanalytics-delta-survey-2013\%281\%29.pdf (Access in 15 de May, 2017)

Dinter, B. (2012). The Maturing of a Business Intelligence Maturity Model. AMCIS 2012. Paper 37.

Drury, D. H. (1983). "An Empirical Assessment of the Stages of DP Growth." MIS Quarterly 7(2): 5.

Duane, A. M. and P. OReilly (2012). A Conceptual Stages of Growth Model for Managing an Organization's Social Media Business Profile (SMBP). ICIS 2012

El Sawy, O. A., ArvindPark, YoungKiPavlou, Paul A (2010). "Research Commentary Seeking the Configurations of Digital Ecodynamics: It Takes Three to Tango." Information Systems Research 21(4): 835- 848.

European Foundation for Quality Management - EFQM. (2011). Modelo EFQM de excelência. Brussels: European Foundation for Quality Management.

Fiss, P. C. (2011). "Building better causal theories: A fuzzy set approach to typologies in organization research." Academy of Management Journal 54(2): 393-420.

Garrett, G. A., \& Rendon, R. G. (2005). Managing contracts in turbulent times: the contract management maturity model. Contract Management, Sept. 2005, 48-57.

Gorschek,T., Nguyen, T., Nguyen, M., Svahnberg, M. Uni-REPM: a framework for requirements engineering process assessment. Published in: Journal Requirements Engineering. Volume 20 Issue 1, March 2015, Pages 91-118.

Hackos, J. T. Information Process Maturity Model. Proc. IEEE Int. Professional Communication Conf. (ProComm), 2017, 1-8

Henriques, Vaughan, and Maureen Tanner. "A systematic literature review of agile and maturity model research." Interdisciplinary Journal of Information, Knowledge, and Management 12 (2017): 053-073.

Japanese Industrial Standards - JIS. (2005). Quality Management System: guidelines for sustainable growth. Tokyo: JIS.

Karkkainen, H., J. Jussila and J. Lyytikkä (2011). "Towards Maturity Modeling Approach for Social Media Adoption in Innovation." 4th ISPIM Innovation Symposium. 
King, J. L. and K. L. Kraemer (1984). "Evolution and organizational information systems: an assessment of Nolan's stage model." Commun. ACM 27(5): 466-475.

Kitchenham, B. Procedures for performing systematic reviews. 2004. ISSN 1353-7776. TR/SE-0401.

Kitchenham, B., Mendes, E., Travassos, G.H. (2007) A Systematic Review of Crossvs. Within-Company Cost Estimation Studies, IEEE Trans on SE, 33 (5),pp 316-329.

Lahrmann, G., F. Marx, T. Mettler, R. Winter and F. Wortmann (2011). Inductive Design of Maturity Models: Applying the Rasch Algorithm for Design Science Research. Service-Oriented Perspectives in Design Science Research, Springer Berlin Heidelberg. 6629: 176-191.

Lehmkuhl, T., U. Baumol and R. Jung (2013). Towards a Maturity Model for the Adoption of Social Media as a Means of Organizational Innovation. HICSS, 2013.

Lockamy, A., \& McCormack, K. (2004). The development of a supply chain management process maturity model using the concepts of business process orientation. Supply Chain Management International Journal (Toronto, Ont.), 9(4), 272-278.

Luftman, J. (2000). "Assessing Business-IT Alignment Maturity." Communications of the Association for Information Systems 4(1): 14.

McCormack, K., Willems, J., Van Den Bergh, J., Deschoolmeester, D., Willaert, P., Indihar Štemberger, M., \& Bosilj Vuksic, V. (2009). A global investigation of key turning points in business process maturity. Business Process Management Journal, $15(5), 792-815$.

Mettler, T., P. Rohner and R. Winter (2010). "Towards a Classification of Maturity Models in Information Systems." Management of the Interconnected World 2010, pp 333-340.

Mullaly, M. P. W. (2014). "If maturity is the answer, then exactly what was the question?" International Journal of Managing Projects in Business 7(2): 169-185.

Nolan, R. L. and C. F. Gibson. (1974). "Managing the Four Stages of EDP Growth." Harvard Business Review January-February 1974.

Paulk, M., B. Curtis, M. Chrissis and C. Weber (2006). "Capability maturity model, version 1.2." Software, IEEE 10.4 (2006): 18-27.

Plattfaut, R., B. Niehaves, J. Pöppelbuß and J. Becker (2011). "Development of BPM capabilities - Is maturity the right path? ", ECIS 2011. Paper 27.

Pöppelbuß, J., B. Niehaves, A. Simons and J. Becker (2011). "Maturity Models in Information Systems Research: Literature Search and Analysis." Communications of the Association for Information Systems 29: 505-532.

Raber, D., F. Wortmann and R. Winter (2013). "Situational Business Intelligence Maturity Models: An Exploratory Analysis". HICSS, 2013.

Raber, D., R. Winter and F. Wortmann (2012). "Using Quantitative Analyses to Construct a Capability Maturity Model for Business Intelligence." HICSS, 2012. 
Renken, J. (2004). "Developing an IS/ICT management capability maturity framework". Proceedings of the 2004 annual research conference of the South African institute of computer scientists and information technologists on IT research in developing countries, South African Institute for Computer Scientists and Information Technologists.

Röglinger, M., J. Pöppelbuß and J. Becker (2012). "Maturity models in business process management". Business Process Management Journal. 18: 328-346.

Royce, Walker. CMM vs. CMMI: from conventional to modern software management. 2002. Disponível em http://www.student.nada.kth.se/ karlm/CMMI.pdf. Access in 24 Jul. 2017.

Rodríguez, N. H. \& Carreira, M. R. Towards a usability maturity model in mobile application development. Proc. 12th Iberian Conf. Information Systems and Technologies (CISTI), 2017, 1-6.

Solli-Sæther, H. and P. Gottschalk (2010). "The modeling process for stage models." Journal of Organizational Computing and Electronic Commerce, 20: 279-293, 2010.

Software, L. L. de Pesquisa em Engenharia de. State of Art in Systematic Review StArt. 2013. Available at http://lapes.dc.ufscar.br/tools/starttool(2013)

Spruit, M. and M. Röling (2014). "ISFAM: The Information Security Focus Area Maturity Model". ECIS 2014.

Singh, P. J., \& Smith, A. (2006). An empirically validated quality management measurement instrument. Benchmarking International Journal (Toronto, Ont.), 13(4), 493-522.

Van De, A. H. and M. S. Poole (1995). "Explaining Development and Change in Organizations." Academy of Management vol. 20 no. 3 510-540.

van Steenbergen, M., R. Bos, S. Brinkkemper, I. van de Weerd and W. and Bekkers (2013). "Improving IS Functions Step by Step: the Use of Focus Area Maturity Models." Scandinavian Journal of Information Systems 25(2): 2.

Steenbergen, M. v., R. Bos, S. Brinkkemper, I. v. d. Weerd and W. Bekkers (2011). "The Design of Focus Area Maturity Models." Global perspectives on design science research. Springer Berlin Heidelberg: 317-332.

Webster, J. and R. T. Watson (2002). "Analyzing the past to prepare for the future: Writing a literature review." MIS Quarterly 26(2): 3.

Weiss, D., J. Repschlaeger, R. Zarnekow and H. and Schroedl (2013). "Towards a Consumer Cloud Computing Maturity Model - Proposition of Development Guidelines, Maturity Domains and Maturity Levels." PACIS 2013. Paper 211.

Wendler, R. (2012). "The maturity of maturity model research: A systematic mapping study." Information and Software Technology 54(12): 1317-1339.

Winkler, T. J., Jochen, Brenner, Walter (2015). "Selfsurvey: A Prediction-Based Decision Support Platform For Survey Research." Twenty-Third European Conference on Information Systems (ECIS), Münster, Germany, 2015. 